\title{
Glycaemic index, palatability and acceptability of energy drinks prepared with $\beta$-glucan and whey protein
}

\author{
${ }^{1}$ Amiruddin, N.E.N, ${ }^{2}$ Zahary, M.N., ${ }^{3}$ Bhaskar, R. and ${ }^{1 *}$ Mhd Jalil, A.M. \\ ${ }^{1}$ School of Nutrition and Dietetics, Faculty of Health Sciences, Universiti Sultan Zainal Abidin (UniSZA), \\ Kampus Gong Badak, 21300, Kuala Nerus, Terengganu, Malaysia \\ ${ }^{2}$ School of Biomedicine, Faculty of Health Sciences, Universiti Sultan Zainal Abidin (UniSZA), Kampus \\ Gong Badak, 21300, Kuala Nerus, Terengganu, Malaysia \\ ${ }^{3}$ School of Rehabilitation Science, Faculty of Health Sciences, Universiti Sultan Zainal Abidin (UniSZA), \\ Kampus Gong Badak, 21300, Kuala Nerus, Terengganu, Malaysia
}

\begin{abstract}
Article history:
Received: 1 October 2019

Received in revised form: 8

October 2019

Accepted: 15 October 2019

Available Online: 26 October 2019
\end{abstract}

\section{Keywords:}

Glycaemic index,

Acceptability,

Palatability,

Satiety,

$\beta$-glucan,

Whey protein

\section{DOI:}

https://doi.org/10.26656/fr.2017.4(2).312

\begin{abstract}
$\beta$-Glucan ( $\beta G$ ) and whey protein (WP) are two functional ingredients widely used to maintain desirable blood glucose and weight management. However, the effect of combining $\beta G$ and WP is still not thoroughly explored. This study was aimed to determine the effects of combining $\beta G$ and WP in energy drinks on glycaemic index (GI), palatability and acceptability. Ten females $\left(22.0 \pm 0.64\right.$ years old, $\left.20.6 \pm 0.24 \mathrm{~kg} / \mathrm{m}^{2}\right)$ randomly completed four trials (control drink, $\beta \mathrm{G}$ drink, WP drink and $\beta \mathrm{G}+\mathrm{WP}$ drink) in a cross-over manner. Palatability and acceptability were measured using visual analogue scale (VAS). Capillary blood was collected at $0 \mathrm{~min}$ (fasting state, baseline) and 15, 30, 60 and $120 \mathrm{~min}$ after the test drinks and assayed for glucose. There were no significant differences in palatability and acceptability of test drinks compared with control $(p>0.005)$. The incremental area under the curve (iAUC) for blood glucose responses showed no significant differences between all test drinks. Time $\mathrm{x}$ treatment showed a significant increased from 0 to 30 mins (peak) $(p<0.005)$ for all test drinks. Blood glucose response significantly $(\mathrm{p}<0.005)$ decreased from 30 to 120 mins for all test drinks except control. There were no significant differences in GI of $\beta \mathrm{G}$, WP, and $\beta \mathrm{G}+\mathrm{WP}$ drinks compared with control $(117 \%, 124 \%$ and $114 \%$, respectively). This study suggested that drinks prepared with $\beta G$ and WP were palatable and acceptable either per se or in combination but did not significantly reduce the GI compared with control drink. In addition, the drink prepared with $\beta \mathrm{G}$ and whey protein reduced short-term glucose but does not affect overall glycaemic response.
\end{abstract}

\section{Introduction}

The glycaemic index (GI) is defined as the percentage of glucose response elicited by a $50 \mathrm{~g}$ of available carbohydrate of a test food compared with reference food (glucose or white bread) (Wolever, 2013; Augustin et al., 2015). Excessive intake of carbohydrate, fat and high GI foods associated with obesity (Cheung et al., 2018). High GI foods rapidly increased glucose level after a meal compared with low GI foods (Augustin et al., 2015; Papakonstantinou et al., 2017). Hence, it is advisable to choose low GI foods to maintain desirable postprandial glucose response. There are many factors that could lower GI in food such as resistant starch, insoluble and soluble fibre content (Alminger et al., 2008; Thondre et al., 2009; Chillo et al., 2011; Panahi et al., 2014).

Dietary fibre is defined as carbohydrate polymers with ten or more monomeric units, which are not hydrolysed by the endogenous enzymes in the small intestine (Jones, 2014). The presence of soluble dietary fibre such as $\beta G$ reduced the glycaemic response and hence lower GI (Panahi et al., 2014). $\beta \mathrm{G}$ is a major constituent of the cell walls in oat and barley endosperm (Chillo et al., 2011). A recent review by Salleh et al. (2019) showed that $\beta \mathrm{G}$ ( 2.5 to $3 \mathrm{~g}$ ) beneficially increased perceived satiety when prepared in solid food (white rice) and beverage (Salleh et al., 2019). $\beta G$ has been approved by the European Food Safety Authority (EFSA) to beneficially reduce glycaemic response (EFSA Panel, 2010). Previous studies showed that $\beta G$ 
prepared in muesli, snack bar, chapati and cereal products reduced postprandial blood glucose compared with control (Alminger et al., 2008; Granfeldt et al., 2008; Thondre et al., 2009; Panahi et al., 2014). The presence of soluble fibre such as $\beta \mathrm{G}$ could lower the glucose response by increasing the stomach viscosity and decreasing intestinal mixing (Edwards et al., 1987; Panahi et al., 2014). Previous study showed that bread prepared with $\beta \mathrm{G}$ significantly reduced early $(30 \mathrm{~min})$ starch hydrolysis compared with control (Jalil et al., 2015). Thondre et al. (2009) suggested that $4 \mathrm{~g}$ of $\beta \mathrm{G}$ in chapati (an Indian flatbread) reduced postprandial blood glucose. However, the preparation of $\beta G$ in a food product or meal negatively affect the taste, palatability and acceptability of the final products (Kim et al., 2016; Zaremba et al., 2018). Most but not all studies showed that $\beta \mathrm{G}$ were less palatable and acceptable (Ktari et al., 2014; Zaremba et al., 2018). One study showed that pasta prepared with $\beta \mathrm{G}$ was palatable and acceptable compared with control (Kim et al., 2016). However, the presence of other food components such as WP might reduce postprandial glucose response (Gunnerud et al., 2013).

Previous study showed that WP beneficially reduces postprandial glucose response (Akhavan et al., 2010; Gunnerud et al., 2013; Zafar et al., 2013; Hutchison et al., 2015; Schopen et al., 2015; Gizenaar et al., 2018). WP accounts for $20 \%$ of cow milk protein and is a byproduct of cheese making (Akhavan et al., 2010). It is rapidly digested and resulting in a quick increase in plasma amino acid (AA) levels (Gunnerud et al., 2013). These AAs showed insulinogenic effects and hence attenuated postprandial blood glucose level (Akhavan et al., 2010). However, it is still unknown whether a combination of $\beta \mathrm{G}$ with WP might have additional glucose-lowering effect. Previous study has shown that the preparation of WP into a drink did not affect the taste of the drink (Zafar et al., 2013). However, Del Giudice et al. (2015) showed that the addition of WP into cow's milk reduced the palatability of the milk. Gursel et al. (2015) showed that $5 \mathrm{~g}$ WP in yoghurt increased the palatability and acceptability compared with control. These inconsistencies might be due to different doses and food matrix used in each study (Salleh et al., 2019).

Food matrix is important to deliver the benefits of both $\beta G$ and WP. Previous study showed liquid food matrix is suitable for the development of functional drinks with soluble fibres (Salleh et al., 2019). Energy drink is defined as group of beverages used by consumers to provide an extra boost in energy, promote wakefulness, maintain alertness and enhancement of mood and cognitive (Ishak et al., 2012). Juvonen et al. (2009) showed that incorporation of $4 \mathrm{~g}$ of $\beta \mathrm{G}$ into a drink produced a significantly lower GI when compared with drinks containing $6 \mathrm{~g}$ and $8 \mathrm{~g}$ of $\beta \mathrm{G}$. Another study by Giezenaar et al. (2018) showed that incorporation of $30 \mathrm{~g}$ WP into a drink produced significantly lower blood glucose in both healthy males and females when compared with control drink. Based on this evidence, this study was aimed to determine the effects of combining $\beta \mathrm{G}$ and WP in energy drink on glycaemic index, palatability and acceptability.

\section{Materials and methods}

\subsection{Study design}

This was a single-blinded, crossover study with Latin square design. Each subject was randomly assigned with a unique code to four study drinks. Participants were not aware of which product they received in each trial. All test drinks have similar taste (chocolate) and colour. Each subject received random sample for each visit separated by three days washout period.

Ten healthy female participants were recruited from Universiti Sultan Zainal Abidin (UniSZA), Kampus Gong Badak, Terengganu with a mean age of $22.2(0.06)$ years old and body mass index (BMI) of $20.06(0.24) \mathrm{kg} /$ $\mathrm{m}^{2}$. This study was approved by Universiti Sultan Zainal Abidin Ethics Committee (UniSZA/UHREC/2018/63). All subjects were given written informed consent before participating in this study. Height and weight of participants were measured using stadiometer SECA Model 217 (SECA, Hamburg, Germany) and SECA Clara 803 (SECA, Hamburg, Germany), respectively. The inclusion criteria were healthy male and female, body mass index (BMI) of $18.5-24.9 \mathrm{~kg} / \mathrm{m}^{2}$ and nondiabetic. The exclusion criteria were overweight or obese, diabetic, on medications or drugs that might interfere with glucose metabolism, pregnant and lactating mother, has food allergies to test ingredients and smokers.

\subsection{Drinks formulation}

There are four types of test drinks as follow: i) control ii) $\beta G$ iii) WP iv) $\beta G+$ WP. All drinks were chocolate-flavoured and containing $50 \mathrm{~g}$ available carbohydrate. The amount of available carbohydrate is achieved from the addition of simple sugar (glucolin) into test drinks. All subjects were given $250 \mathrm{~mL}$ of each test drinks during each session. Table 1 shows nutrients composition of test drinks. $\beta \mathrm{G}$ (Oat Beta 1,3/1,4 Glucan, Zhuhai City, China) has $80 \%$ purity meanwhile WP (Mesotropin Platinum Hydro Whey, Terengganu, Malaysia) has $70 \%$ purity. All $\beta G$ containing drinks contain $4 \mathrm{~g} \beta \mathrm{G}$ per $250 \mathrm{~mL}$ and all WP-containing drinks contain $5 \mathrm{~g}$ WP per $250 \mathrm{~mL}$. 
Table 1. Nutrients composition of test drinks (per $250 \mathrm{~mL}$ ).

\begin{tabular}{lcccc}
\hline & Control drink & $\beta \mathrm{G}$ drink & WP drink & $\beta \mathrm{G}+$ WP drink \\
\hline Energy (kcal) & 237 & 255 & 257 & 275 \\
Carbohydrate $(\mathrm{g})$ & 50 & 50 & 50 & 50 \\
$\beta$-Glucan $(\mathrm{g})$ & - & 4 & - & 4 \\
Protein $(\mathrm{g})$ & 1.2 & 3.6 & 6.2 & 8.6 \\
Fat $(\mathrm{g})$ & 3.6 & 3.6 & 3.6 & 3.6 \\
\hline
\end{tabular}

\subsection{Experimental procedures}

Participants were instructed to eat their dinner no later than 10:00 pm and fast for $10 \mathrm{hrs}$ prior to the laboratory visit. Plain water was allowed during fasting period. Participants arrived at 8:00 am and were advised to rest for 10 mins upon arriving in the laboratory. Glycaemic index for the test drinks in this study was determined using the standard GI protocol (Wolever et al., 1991). Fasting blood sample $(\mathrm{t}=0 \mathrm{~min}$, baseline $)$ was obtained and the test meal was given immediately. Participants were advised to consume the meal at their own pace within 10 to 12 mins. This time was selected based on the pilot study. Postprandial blood was obtained thereafter at $15,30,60$, and 120 mins Participants were allowed to read, use their phone or laptop and use the toilet during the trial. Blood glucose level was determined using Accu-Chek Performa 2 glucometer (Accu Check Performa, New South Wales, Australia). Calibration was done using a standard glucose strip provided by the manufacturer. The glycaemic index was calculated according to Wolever et al. (2008) as follow:

\subsection{Palatability and acceptability test}

$$
\frac{\text { iAUC test drinks }}{\text { iAUC control drinks }} \times 100
$$

The palatability and acceptability of energy drinks were measured using Adaptive Visual Analogue Scale (AVAS) software (Marsh-Richard et al., 2009). There was a horizontal line in the AVAS software with a score range 0 at the left and 100 on the right. The participants evaluated the appearance, taste, aroma, viscosity, perceived satiety and overall acceptability of the energy drinks. A higher score indicates a higher acceptability of the energy drinks. The score of 0 indicates they dislike and the score of 100 indicates they like the energy drinks. They were explained on how to do the scoring using AVAS before each session.

\subsection{Data analysis}

Data were analysed using IBM SPSS (IBM Corp. Released 2013. IBM SPSS Statistics for Windows version 22.0, Armonk, NY). Data are expressed as mean and standard error of the mean (SEM) and values of $\mathrm{p}<0.05$ were considered statistically significant. The incremental area under the curve (iAUC) of blood glucose responses were calculated for each test drink and the glycaemic index was calculated from the iAUC of each subject. One way ANOVA was used to determine the mean GI, palatability and acceptability. ANOVA repeated measures was used to determine the differences in blood glucose response at different time points.

\section{Results}

\subsection{Sensory evaluation of test drinks}

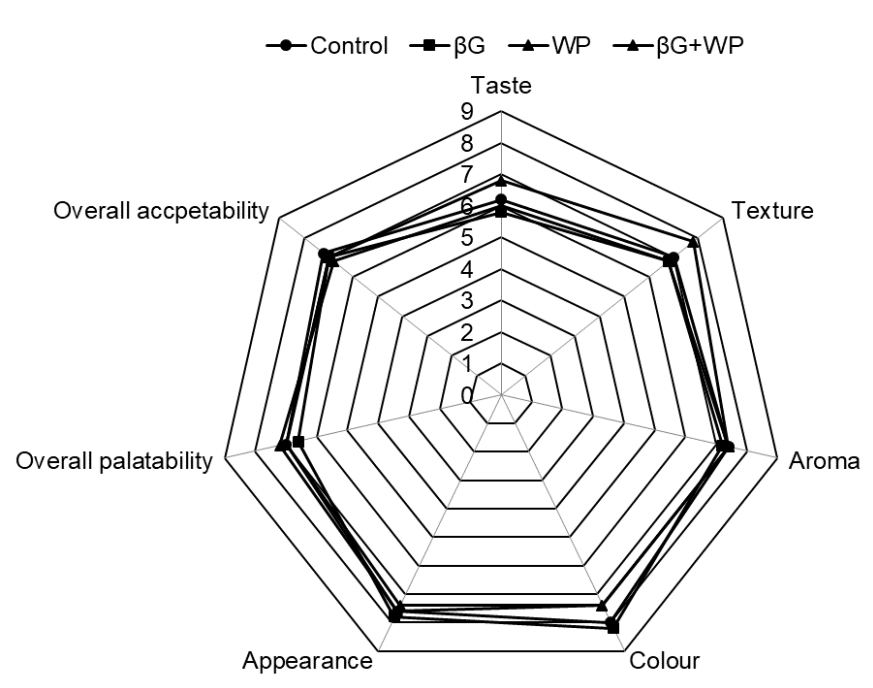

Figure 1. Sensory evaluation of four test drinks. A higher score indicates a higher acceptability of the test drinks. $\beta \mathrm{G}, \beta$ glucan; WP, whey protein

Figure 1 shows the sensory evaluation of test drinks, namely, taste, colour, texture, aroma, appearance, overall palatability and overall acceptability. The taste scores were similar between control, WP, $\beta \mathrm{G}$ and $\beta \mathrm{G}+\mathrm{WP}$ drink with $6.2(0.87), 6(0.63), 5.8(0.60)$, and $6.8(0.68)$, respectively $(\mathrm{p}=0.57)$. Control, $\mathrm{WP}$, and $\beta \mathrm{G}+\mathrm{WP}$ drink showed similar aroma scores with $7.4(0.30)$, except for $\beta G$ drink with $7.2(0.61)(p=0.34)$ The texture scores were similar between control, $\beta \mathrm{G}, \mathrm{WP}$ and $\beta \mathrm{G}+\mathrm{WP}$ drinks with 7 (0.54), 6.8 (0.53), 6.8 (0.53), and 7.8 (0.36), respectively $(p=0.13)$. The colour scores were similar between control, $\beta \mathrm{G}$, WP and $\beta \mathrm{G}+\mathrm{WP}$ drinks with 8.0 (0.52), $8.2(0.47), 7.4(0.73)$ and $7.4(0.52)$, respectively $(\mathrm{p}=0.72)$. The appearance scores were similar between control, $\beta \mathrm{G}$, WP and $\beta \mathrm{G}+\mathrm{WP}$ drinks 
with $7.6(0.40), 7.8(0.47), 7.6(0.58)$ and $7.4(0.52)$, respectively $(\mathrm{p}=0.81)$. The overall palatability scores were similar between control, WP, $\beta \mathrm{G}+\mathrm{WP}$ and $\beta \mathrm{G}$ drinks with $7.0(0.45), 7.2(0.60), 7.0(0.80)$, and 6.6 $(0.45)$, respectively $(\mathrm{p}=0.08)$. The overall acceptability scores were similar between control, $\beta \mathrm{G}, \beta \mathrm{G}+\mathrm{WP}$ and WP drinks with $7.2(0.68), 7.0(0.45), 7.0(0.74)$, and 6.8 $(0.45)$, respectively $(\mathrm{p}=0.11)$.

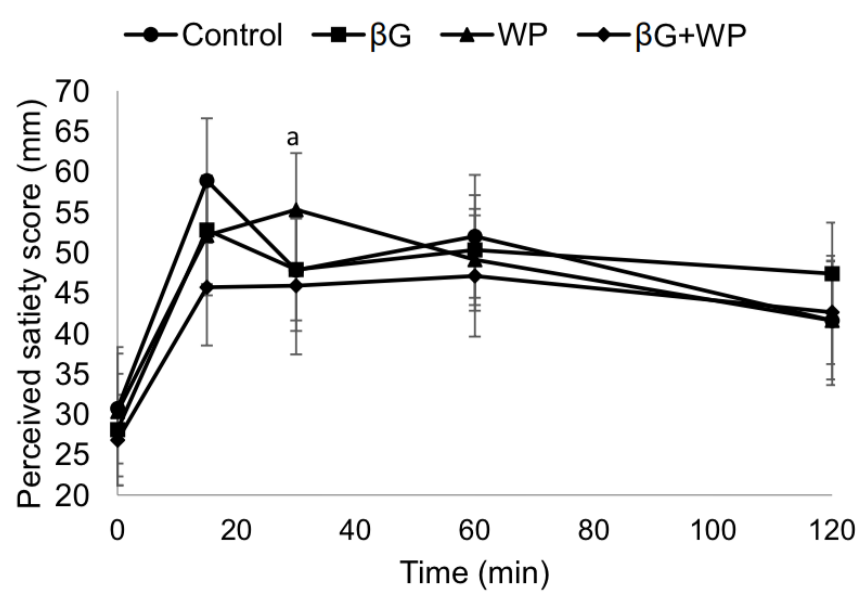

Figure 2(a). Perceived satiety score for all test drinks (0 to 120 mins). $\beta \mathrm{G}, \beta$-glucan; $\beta \mathrm{G}+\mathrm{WP}, \beta$-glucan and whey protein. The alphabet represents significant time $\mathrm{x}$ treatment interactions $(p<0.05)$. a: 0 vs 30 min for control drink.

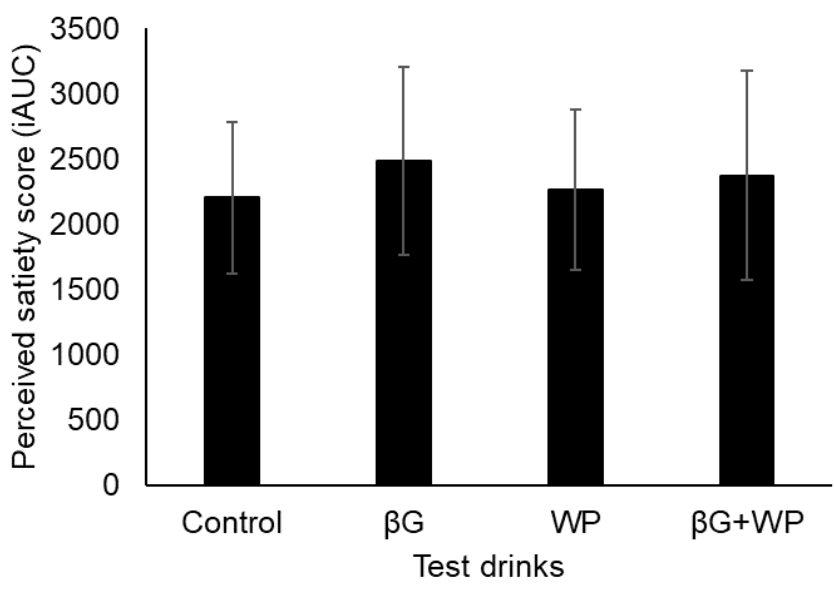

Figure 2(b) Incremental area under the curve for perceived satiety score for all test drinks. $\beta \mathrm{G}+\mathrm{WP}, \beta$-glucan and whey protein.

\subsection{Perceived satiety}

Figure 2(a) shows the mean perceived satiety (PS) score for test drinks from 0 to 120 mins. There were no significant $(\mathrm{p}>0.05)$ differences in the mean PS scores for all test drinks. Both control and $\beta G$ drinks achieved their PS peak at 15 mins after the consumption of the test drink. Meanwhile, WP and $\beta \mathrm{G}+\mathrm{WP}$ drinks achieved their PS peak at 30 mins and 60 mins after the consumption of the test drink. The PS scores were similar for all drinks at 2 hrs. Perceived satiety significantly $(\mathrm{p}=0.04)$ increased between 0 and 30 mins for control drink. Control drink showed a significant reduction in PS 30 mins after it was consumed and 15 mins after it reached its peak $(p=0.037)$. This suggested that PS was rapidly increased and decreased following the control drink consumption. However, other test drinks showed no significant time and treatment interactions ( $>0.05$ ). Figure 2(b) shows the iAUC for perceived satiety score from 0 to 120 mins. The iAUC was similar between control, $\beta \mathrm{G}$, WP and $\beta \mathrm{G}+\mathrm{WP}$ drinks with $2205 \pm 581.1 \mathrm{~mm} \times \mathrm{min}, 2484 \pm 719.8$ $\mathrm{mm} \times \mathrm{min}, 2266 \pm 615.5 \mathrm{~mm} \times \mathrm{min}$, and $2372 \pm 804.2 \mathrm{~mm}$ $\mathrm{x}$ min, respectively.

\subsection{Prospective food consumption}

Figure 3(a) shows the mean scores of prospective food consumption for all test drinks from 0 to 120 mins. There were no significant differences in the mean score of prospective food consumption for all test drinks $(p=0.90)$. Figure $3(b)$ shows the iAUC for prospective food consumption score from 0 to $120 \mathrm{~min}$. The iAUC was similar for control, $\beta \mathrm{G}$, WP and $\beta \mathrm{G}+\mathrm{WP}$ drinks with $320.6 \pm 178.7 \mathrm{~mm} x \mathrm{~min}, 390.1 \pm 275.1 \mathrm{~mm} \times \mathrm{min}$, $837.2 \pm 398.5 \mathrm{~mm} \times \mathrm{min}$ and $186.8 \pm 113.8 \mathrm{~mm} \times \mathrm{min}$, respectively $(\mathrm{p}=0.35)$. There was no significant time and

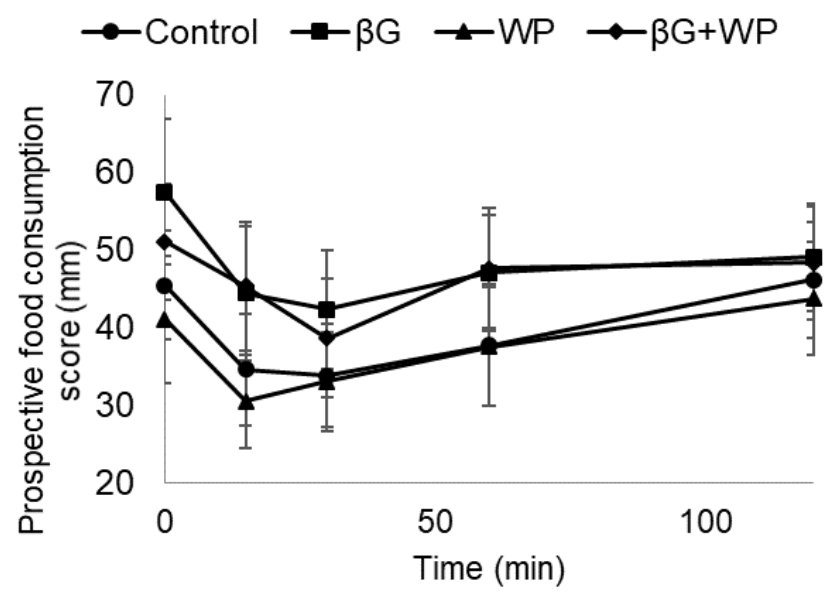

Figure 3(a). Prospective food consumption score for all test drinks ( 0 to 120 mins). $\beta \mathrm{G}, \beta$-glucan; $\beta \mathrm{G}+\mathrm{WP}, \beta$-glucan and whey protein.

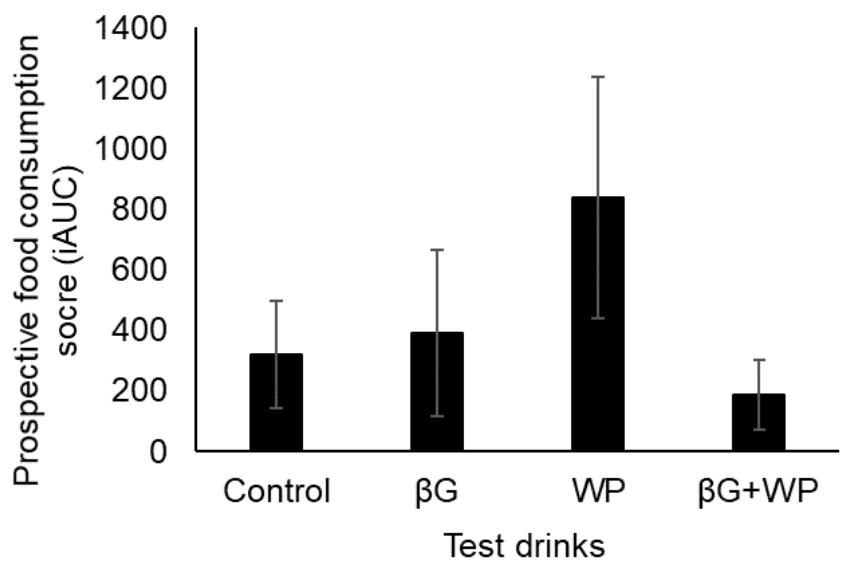

Figure 3(b). Incremental area under the curve for prospective food consumption score for all test drinks. $\beta \mathrm{G}, \beta$-glucan; $\beta \mathrm{G}+\mathrm{WP}, \beta$-glucan and whey protein. 
treatment interactions $(\mathrm{p}>0.05)$.

\subsection{Blood glucose response}

Figure 4(a) shows the postprandial glucose response of the drinks from 0 to 120 mins. All test drinks showed a maximum glucose peak at 30 mins after the consumption of the drinks. There were no significant differences in the blood glucose response between test drinks at $0,15,30,60$ and 120 mins $(p=0.37)$. Figure 4 (b) shows the incremental area under the curve (iAUC) for test drinks from 0 to 120 mins. The iAUC was similar between control, $\beta \mathrm{G}, \mathrm{WP}$, and $\beta \mathrm{G}+\mathrm{WP}$ drinks with $222.2 \pm 31.4 \mathrm{~mm} x \mathrm{~min}, 239 \pm 22.3 \mathrm{~mm} \times \mathrm{min}, 237 \pm 20.5$ $\mathrm{mm} \times \mathrm{min}$, and $236 \pm 31 \mathrm{~mm} \mathrm{x}$ min, respectively $(p=0.53)$. There were significant $(p<0.05)$ time and treatment interactions. All test drinks showed a significant increased from 0 to 30 mins (peak) $(\mathrm{p}<0.005)$. $\beta G$, WP and $\beta G+W P$ drinks significantly $(\mathrm{p}<0.05)$ reduced glucose response from 30 to 120 mins. $\beta G$ and/ or WP drinks showed highest maximum glucose peak but significantly $(\mathrm{p}<0.005)$ reduced to baseline after 120 mins compared with control. Control and $\beta \mathrm{G}+\mathrm{WP}$ drinks showed significantly $(\mathrm{p}<0.005)$ lower glucose response from 60 to $120 \mathrm{~min}$. This suggested that blood glucose level remained higher at 60 mins compared with baseline for control and $\beta \mathrm{G}+\mathrm{WP}$ drinks. Glycaemic index for $\beta \mathrm{G}+\mathrm{WP}, \beta \mathrm{G}$ and WP drinks were $114 \%(0.97), 117 \%$ (0.98) and 124\% (0.98), respectively (Figure 4 (c)). Based on the GI classification, these drinks were categorised as high GI.

\section{Discussion}

Our study shows that the addition of $\beta G$ and/or WP in energy drink did not alter the palatability and acceptability of the drinks compared with control. In contrast, previous studies showed that the addition of $\beta G$ and WP reduced the acceptability and palatability of the food products, such as pasta and yoghurt (Gursel et al., 2015; Zaremba et al., 2018). Oral-sensory exposure time was higher for solid food due to higher eating time and this might explain the palatability differences between solid and liquid foods (Cassady et al., 2012). Zaremba et al. (2018) showed that preparation of breakfast meal (cereal and yoghurt) with $4 \mathrm{~g}$ of oat $\beta \mathrm{G}$ significantly reduced the palatability of the meal compared with control meal. However, another study showed the preparation of Tunisian beef sausages with $0.5 \mathrm{~g} \beta \mathrm{G}$ concentrate significantly increased the acceptability compared with control sausage (Ktari et al., 2014). Pasta prepared with $2 \% \beta \mathrm{G}$ rich fraction ( $\beta \mathrm{GRF}$ ) mushroom powder showed higher acceptability compared with pasta with $4 \%$ and $6 \%$ GGRF mushroom powder (Kim et al., 2016). These results suggested that the addition of $\beta G$ into various food products could alter the acceptability and palatability in a dose-dependent manner. A lower dose of $\beta G$ can enhance the acceptability and palatability of the food products, but the effect diminished at higher dose (Ktari et al., 2014; Kim et al., 2016; Zaremba et al., 2018). The evidence has shown that $\beta G$ could increase perceived satiety. However, other food components such as WP could give better effects when combined together with $\beta \mathrm{G}$.

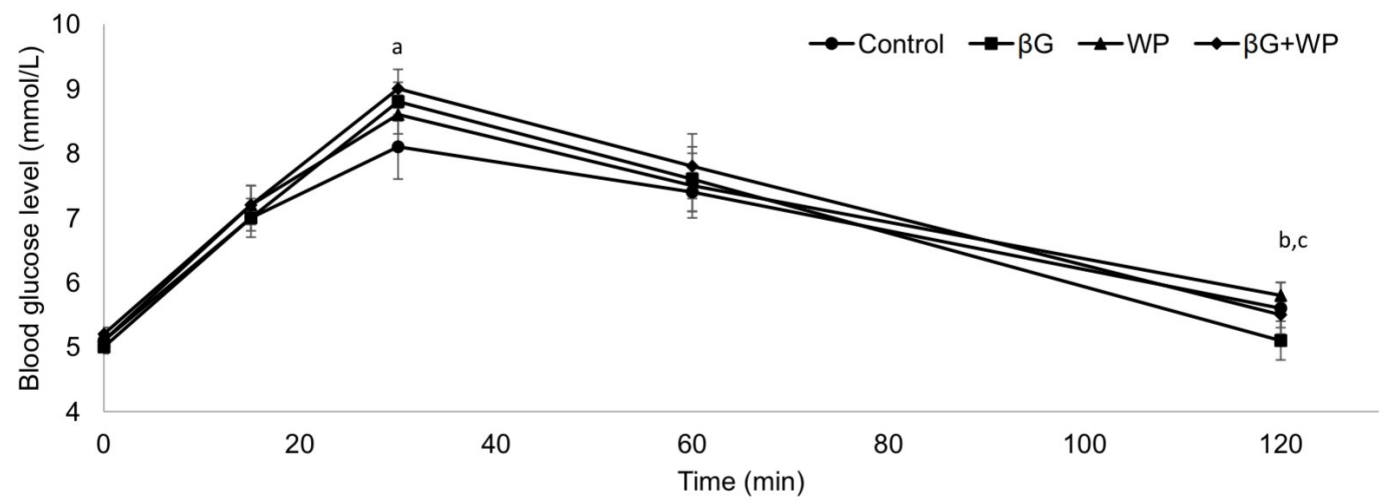

Figure 4(a). Postprandial glucose response for test drinks (0 to 120 mins). $\beta G, \beta$-glucan; WP, whey protein. Different letters represent significant time $\mathrm{x}$ treatment interactions $(\mathrm{p}<0.05)$.a: 0 vs 30 mins for all drinks; b: 30 vs 120 mins for $\beta G$, WP and $\beta G+W P$ drinks; c: 60 vs 120 mins for control and $\beta G+W P$ drink

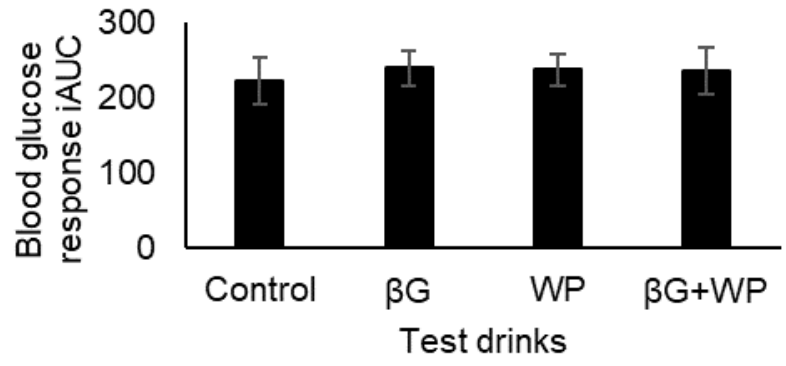

Figure 4(b). Blood glucose responses iAUC of test drinks

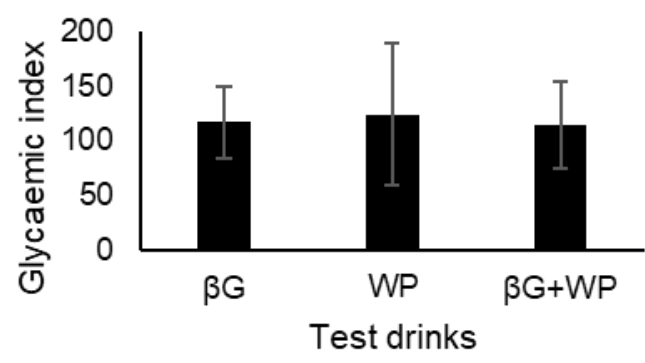

Figure 4(c). Glycaemic index of test drinks 
Gursel et al. (2015) showed the addition of $15 \mathrm{~g} \mathrm{WP}$ isolate into a yoghurt significantly reduced its flavour compared with control yoghurt. Another study showed that a higher dose of WP $(25 \mathrm{~g})$ did not alter the palatability of the drink compared with control drink (Zafar et al., 2013). These results suggested that the addition of WP, even in a higher dosage, did not alter the taste of the products. This may be attributable to the same amount of the nutrient content of the test drinks. All drinks were matched for their sweetness, fat and also containing $50 \mathrm{~g}$ of available carbohydrate, thus the addition of a high dose of WP did not cause any differences in the taste of the drinks (Zafar et al., 2013). In contrast, a study conducted by Gursel et al. (2015) did not match for total sugar and fat content. These factors might have contributed to the differences observed in the taste of the test meals. In our study, only small amount of $\beta \mathrm{G}$ and WP used (4 $\mathrm{g}$ and $7 \mathrm{~g}$, respectively). The previous study showed that a lower dose of whey increased palatability of reduced-fat ice cream compared with control (Danesh et al., 2017). All test drinks containing $50 \mathrm{~g}$ of available carbohydrate, the same amount of fat and hence isocaloric. Hence, this could be the reason why all test drinks showed similar palatability and acceptability. Theoretically, satiety and sensory characteristics of food drive food choice (Blundell et al., 2010). Hence, our next objective was to determine the effect of test drinks on perceived satiety.

Our study showed that both $\beta \mathrm{G}$ and WP did not further increase perceived satiety and suppressed the feeling of hunger compared with control. Perceived satiety is described as the period between meals (after food consumption) and the process occurring in that time period (Gibbons et al., 2019). Perceived satiety is measured through visual analogue scales (VAS), in which participants are allowed to place a mark on a 100 $\mathrm{mm}$ horizontal line to reflect the intensity of their satiety sensation at a particular time (Gibbons et al., 2019). Our study showed that both $\beta G$ and WP increased perceived satiety and suppressed the feeling of hunger compared with control. Lumaga et al. (2011) showed that $\beta \mathrm{G}$ enriched beverages increased perceived fullness by $24 \%$, and subsequently reduced energy intake by $30 \%$ over 24 hrs compared with control. $\beta G$ has the ability to form a viscous solution in the gut, which underpinned the satiety effect of $\beta G$. $\beta G$ increased viscosity in the gut when prepared into test beverage and subsequently slowing down gastric emptying rate (Juvonen et al., 2009). The same study showed that high-viscosity drink slowing down gastric emptying rate compared with lowviscosity beverage.

There is another food component such as WP that might reduce perceived hunger and increased perceived satiety (Hutchison et al., 2015; Giezenaar et al., 2018). Mechanistically, WP stimulates the release of cholecystokinin (CCK), peptide YY (PYY), gastric inhibitory polypeptide (GIP) and glucagon-like peptide 1 (GLP-1) and suppress hunger hormones such as ghrelin (Hall et al., 2003; Hutchison et al., 2015). A study conducted by Hall et al. (2003) showed WP preload increased GIP and GLP-1 with $6.7 \%$ and $12.7 \%$, respectively, compared with preload casein drink (control). Preload WP drink increased perceived satiety (fullness) by $22 \%$ compared with casein drink (Hall et al., 2003). Our study showed that $\beta G$, alone or in combination with WP had no effect on perceived satiety compared with control drink. A study showed that protein supplementation had lower satiating effect in young women than men (Giezenaar et al., 2018). This is in line with our study, in which all participants were young women. However, another study by Bedard et al. (2015) showed women had greater reduction in appetite, hunger and desire to eat score compared with men after a Mediterranean meal $(-86.1 \%$ vs $-77.6 \%$ for appetite score, $-88.5 \%$ vs $-80.3 \%$ for hunger score and $-87.7 \%$ vs $-79.3 \%$ for desire to eat, respectively). A study by Westerterp-Plantenga et al. (2009) also showed women have greater changes in appetite sensation compared with men when given a diet high in protein $(30 \%$ of energy) compared with a diet lower in protein $(10 \%$ of energy). In our study, all-female participants received a low protein- energy drink ( $10 \%$ of energy). This may explain the same perceived satiety score when compared with control.

Previous studies showed that incorporation of $\beta G$ into various food products has beneficial effects on perceived satiety and positively regulated glucose response (Finocchiaro et al., 2011; Thondre et al., 2012; Panahi et al., 2014). However, in our study, preparing energy drinks with $\beta \mathrm{G}$ and/or WP did not significantly reduce postprandial blood glucose response, and hence the glycaemic index of the drinks. Theoretically, $\beta \mathrm{G}$ gelatinized, increased gut viscosity and subsequently delayed the glucose absorption into the blood circulation and hence, reduced postprandial glucose response (Panahi et al., 2014). Poppitt et al. (2007) showed that $\beta G$ reduced area under the curve (AUC) for glucose response when prepared in solid food compared with liquid. However, Makelainen et al. (2007) showed that 2, 4 and $6 \mathrm{~g} \beta \mathrm{G}$ in test drinks resulted in a lower GI compared with control drink. This contradictory result from the previous study may be due to the presence of added oat starch in the drink to achieve a total of $50 \mathrm{~g}$ of available carbohydrate. Starch is a complex carbohydrate that plays an important role in the development of fibreinduced small intestine viscosity (Poppitt et al., 2007). The presence of oat starch has an additional step in the 
digestion process as it requires amylase digestion, thus attenuated the increase of postprandial blood glucose (Poppitt et al., 2007). However, our study showed that the addition of $\beta G$ had no effect on blood glucose. This may be attributable to the possibility of insufficient time of $\beta G$ to form a viscous solution within the gut. In our study, $50 \mathrm{~g}$ available carbohydrate was achieved by the addition of only simple sugar, which is rapidly digested, hence rapid increase in the postprandial blood glucose level. Besides $\beta G$, there is also another food component that can reduce postprandial glucose such as WP.

As oppose to the previous study, our study showed that WP ingestion did not significantly reduce glucose response compared with control drink. WP is rapidly digested and resulted in a rapid increase in amino acids (AAs) (Akhavan et al., 2010). These AAs, especially branched amino acid (BCAA), such as leucine, isoleucine and valine, has an insulinogenic effect (Gunnerud et al., 2013). Thus, WP ingestion resulted in a rapid increase in insulin, which underpinned the bloodglucose-lowering effect of WP (Schopen et al., 2017). Previous study showed that the addition of $30 \mathrm{~g}$ WP in drink reduced glucose response in male and female compared with control drink (Giezenaar et al., 2018). As opposed to the previous study, our study showed that WP ingestion did not significantly reduce glucose response compared with control drink. This finding may be due to the different dose of WP used. A study by Claessans et al. (2009) showed a significant reduction in glucose after consumption of $15 \mathrm{~g}$ WP hydrolysate compared with control. The current study also using the same type of WP hydrolysate but using a lower dose of $5 \mathrm{~g}$. However, there was no significant difference in glucose response of the drink compared with control. These results may have suggested that the dose used in the current study was inadequate to produce a significant effect of WP on glucose response. Besides, some AAs such as alanine and glutamine are glucogenic (Engelking, 2015). These AAs are used as a precursor to producing glucose via gluconeogenesis, especially during a starvation state (Engelking, 2015). Gluconeogenesis occurs mainly in liver and kidney and using non-carbohydrate substrates, namely glycerol, lactate, propionate and glucogenic amino acids to form glucose-6-phosphate (G6P). Glucose-6-phosphate will be transformed to free glucose or glycogen (Engelking, 2015). It is estimated that amino acids contributed about $5-7 \%$ of glucose during fed and fasted state (Engelking, 2015). This may cause additional glucose released into the blood circulation after the ingestion of the WP drink. The presence of glucogenic $\mathrm{AA}$ in the test drinks may be used for gluconeogenesis and subsequently increased glucose response compared with control drink. $\beta G$ and WP when consumed alone, can significantly reduce blood glucose response and can increase perceived satiety. Thus, they become widely consumed as it could be an effective method to reduce the glycaemic index of food or drink. However, no evidence of the effect of $\beta G$ and WP on blood glucose response when consumed together. This study found that combining both $\beta G$ and WP in an energy drink did not significantly reduce blood glucose response and glycaemic index of the drink. These findings provide opportunities for the consumer to reconsider consuming the intact form of $\beta \mathrm{G}$ and WP sources such as barley and oat rather than consuming the processed one (powder form). However, this study had several limitations, which include limited time to conduct study. This limitation leads to a short washout period between trials, which may cause a carry-forward effect from previous trial. Besides, the nutritional contents of the energy drinks were calculated manually. This factor may cause inaccurate nutritional contents of energy drinks compared when determined using food analysis.

\section{Conclusion}

This study suggests that palatability and acceptability of drinks prepared with $\beta G$ and WP were similar compared to the control drink. The test drinks significantly reduced postprandial blood glucose response compared with control. However, there was no additional effect of adding $\beta \mathrm{G}$ with WP on perceived satiety and GI. WP supplement ( $5 \mathrm{~g}$ per $250 \mathrm{~mL})$ is high in GI and costly, thus, there is a need to re-think about its consumption. It is advisable to make full use of natural sources of protein and $\beta G$ such as milk and oatmeal or barley for better glucose control. A higher dose of WP and a combination with other soluble fibres such as guar gum and alginate might give a better effect but this needs to be confirmed in human study.

\section{Conflict of Interest}

The authors declare no conflict of interest.

\section{Acknowledgements}

The authors would like to acknowledge Universiti Sultan Zainal Abidin for the funding through Special Research Grant Scheme (UniSZA/2017/SRGS/14, Grant No R0019-R014) and all subjects involved in this trial.

\section{References}

Akhavan, T., Luhovyy, B.L., Brown, P.H., Cho, C.E. and Anderson, G.H. (2010). Effect of premeal consumption of whey protein and its hydrolysate on food intake and postmeal glycemia and insulin 
responses in young adults. The American Journal of Clinical Nutrition, 91, 966-975. https:// doi.org/10.3945/ajen.2009.28406.

Alminger, M. and Eklund-Jonsson, C. (2008). Wholegrain cereal products based on a high-fibre barley or oat genotype lower post-prandial glucose and insulin responses in healthy humans. European Journal of Nutrition, 47, 294-300. https://doi.org/10.1007/ s00394-008-0724-9.

Augustin, L.S.A., Kendall, C.W.C., Jenkins, D.J.A. and Willet, W.C. (2015). Glycemic index, glycemic load and glycemic response: An International Scientific Consensus Summit from the International Carbohydrate Quality Consortium (ICQC). Nutrition, Metabolism and Cardiovascular Diseases, 25(9), 795-815. https://doi.org/10.1016/ j.numecd.2015.05.005.

Bedard, A., Hudon, A.M., Drapeau, V., Corneau, L., Dodin, S. and Lemieux, S. (2015). Gender differences in the appetite response to a satiating diet. Journal of Obesity, 2015, 1-9. http:// dx.doi.org/10.1155/2015/140139.

Blundell, J., De Graaf, C., Hulshof, T., Jebb, S., Livingstone, B., Lluch, A., Mela, D., Salah, S., Schuring, E., Van Der Knaap, H. and Westerterp, M. (2010). Appetite control: methodological aspects of the evaluation of foods. Obesity Review, 11(3), 251270. https://doi.org/10.1111/j.1467789X.2010.00714.x.

Cassady, B.A., Considine, R.V. and Mattes, R.D. (2012). Beverage consumption, appetite, and energy intake: what did you expect? American Journal of Clinical Nutrition, 95, 587-593. https:// doi: 10.3945/ ajcn.111.025437.

Cheung, L.T.F, Ko, G.T.C., Chow, F.C.C. and Kong, A.P.S. (2018). Association between hedonic hunger and glycemic control in non-obese and obese patients with type 2 diabetes. Journal of Diabetes Investigation, 9(5), 1135-1143. https:// doi.org/10.1111/jdi.12800.

Chillo, S., Ranawana, D.V., Pratt, M. and Henry, J.K. (2011). Glycemic response and glycemic index of semolina spaghetti enriched with barley $\beta$-glucan. Nutrition, 27(3), 653-658. https://doi.org/10.1016/ j.nut.2010.07.003.

Claessans, M., Calame, W., Siemensma, A.D., Van Baak, M.A. and Saris, W.H.M. (2009). The effect of different protein hydrolysate/carbohydrate mixtures on postprandial glucagon and insulin responses in healthy subjects. European Journal of Clinical Nutrition, 63, 48-56. https://doi.org/10.1038/ sj.ejcn.1602896.
Del Giudice, M.M., D’Auria, E., Peroni, D., Palazzo, S., Radaelli, G., Comberiati, P., Galdo, F., Maiello, N. and Riva, E. (2015). Flavour, relative palatability and components of cow's milk hydrolysed formulas and amino acid-based formula. Italian Journal of Paediatrics, 41, 42. https://doi.org/10.1186/s13052015-0141-7.

Edwards, C.A., Blackburn, N.A., Craigen, L., Davison, P., Tomlin, J., Sugden, K., Johnson, I.T. and Read, N.W. (1987). Viscosity of food gums determined in vitro related to their hypoglycemic actions. American Journal of Clinical Nutrition, 46(1), 72-77. https:// doi.org/10.1093/ajen/46.1.72.

EFSA Panel on Dietetic products, Nutrition and Allergies (NDA). (2010). Scientific opinion on dietary reference for carbohydrates and dietary fibre. EFSA Journal, 8(3), 1462. https://doi.org/10.2903/ j.efsa.2010.1462.

Engelking, L.R. (2015). Gluconeogenesis. Textbook of Veterinary Physiological Chemistry. $3^{\text {rd }}$ ed., p. 225230. USA: Academic Press

Finocchiaro, F., Ferrari, B., Gianinetti, A., Scazzina, F., Pellegrini, N., Caramanico, R. and Stanca, A.M. (2012). Effects of barley $\beta$-glucan-enriched flour fractions on the glycaemic index of bread. International Journal of Food Sciences and Nutrition, 63(1), 23-29. https:// doi.org/10.3109/09637486.2011.593504.

Gibbons, C., Hopkins, M., Beaulieu, K., Oustric, P. and Blundell, J.E. (2019). Issues in measuring and interpreting human appetite (satiety/satiation) and its contribution to obesity. Current Obesity Reports, 8 (2), 77-87. https://doi.org/10.1007/s13679-01900340-6.

Giezenaar, C., Luscombe-Marsh, N.D., Hutchison, A.T., Lange, K., Hausken, T., Jones, K.L., Horowitz, M., Chapman, I. and Soenen, S. (2018). Effect of gender on the acute affects of whey protein ingestion on energy intake, appetite, gastric emptying and gut hormone responses in healthy young adults. Nutrition and Diabetes, 8, 40. https:/ doi.org/10.1038/s41387-018-0048-7.

Granfeldt, Y., Nyberg, L. and Bjorck, I. (2008). Muesli with $4 \mathrm{~g}$ oat $\beta$-glucans lowers glucose and insulin responses after a bread meal in healthy subjects. European Journal of Clinical Nutrition, 62, 600-607. https://doi.org/10.1038/sj.ejcn.1602747.

Gunnerud, U.J., Ostman, E.M. and Bjorck, I.M.E. (2013). Effects of whey proteins on glycaemia and insulinaemia to an oral glucose load in healthy adults; a dose-response study. European Journal of Clinical Nutrition, 67, 749-753. https:// doi.org/10.1038/ejen.2013.88. 
Gursel, A., Gursoy, A., Anli, E.A.K., Budak, S.O., Aydemir, S. and Durlu-Ozkaya, F. (2015). Role of milk protein based products in some quality attributes of goat milk yoghurt. Journal of Dairy Science, 99(4), 1-10. http://dx.doi.org/10.3168/ jds.2015-10393.

Hall, W.L., Millward, D.J., Long, S.J. and Morgan, L.M. (2003). Casein and whey exert different effects on plasma amino acid profiles, gastrointestinal hormone secretion and appetite. British Journal of Nutrition, 89(2), 239-348. https:// doi.org/10.1079.BJN2002760.

Hutchison, A.T., Piscitelli, D., Horowitz, M., Jones, K.L., Clifton, P.M., Standfield, S., Hausken, T., Feinle Bisset, C. and Luscombe-Marsh, N.D. (2015). Acute load-dependent effects of oral whey protein on gastric emptying, gut hormones release, glycemia, appetite, and energy intake in healthy men. American Journal of Clinical Nutrition, 102(6), 1574-1584. https://doi.org/10.3945/ajcn.115.117556.

IBM Corp. Released 2013. IBM SPSS Statistics for Windows, Version 22.0. Armonk, NY: IBM Corp.

Ishak, W.W., Ugochukwu, C., Bagot, K., Khalili, D. and Zaky, C. (2012). Energy drinks. Innovations in Clinical Neuroscience, 9(1), 25-34.

Jalil, A.M., Edwards, C.A., Combet, E., Ibrahim, M. and Garcia, A.L. (2015). Combined effects of added beta glucan and black tea in breads on starch functionality. International Journal of Food Sciences and Nutrition, 66(2), 1-7. https:// doi.org/10.3109/09637486.2014.971225.

Jones, J.M. (2014). CODEX-aligned dietary fiber definitions help to bridge the "fiber gap." Nutrition Journal, 13, 34. https://doi.org/10.1186/1475-289113-34.

Juvonen, K.R., Purhonen, A-K., Salmenkallio-Marttila, M., Lahteenmaki, L., Laaksonen, D.E., Herzig, K.H., Uusitupa, M.I.J., Poutanen, K.S. and Karhunen, L.J. (2009). Viscosity of oat bran-enriched beverages influences gastrointestinal hormonal responses in healthy humans. Journal of Nutrition, 139(3), 461466. https://doi.org/10.3945/jn.108.099945.

Ktari, N., Smaoui, S., Trabelsi, I., Nasri, M. and Salah, R.B. (2014). Chemical composition, technofunctional and sensory properties and effects of three dietary fibres on the quality characteristics of Tunisian beef sausage. Meat Science, 96(1), 512525.

http://dx.doi.org/10.1016/ j.meatsci.2013.07.038.

Lumaga, R.B., Azzali, D., Fogliano, V., Scalfi, L. and Vitaglione, P. (2011). Sugar and dietary fibre consumption influence, by different hormonal responses, the satiating capacity of a fruit-based and a $\beta$-glucan-enriched beverage. Food and Function, 3 (1), 67-75. https://doi.org/10.1039/c1fo10065c.

Makelainen, H., Anttila, H., Sihvonen, J., Hietanen, R.M., Tahvonen, R., Salminen, E., Mikola, M. and Sontag-Strohm, T. (2007). The effect of $\beta$-glucan on the glycemic and insulin index. European Journal of Clinical Nutrition, 61, 779-785. https:// doi.org/10.1038/sj.ejen.1602561.

Marsh-Richard, D.M., Hatzis, E.S., Mathias, C.W., Venditti, N. and Dougherty, D.M. (2009). Adaptive visual analog scale (AVAS): A modifiable software program for the creation, administration and scoring of visual analog scales. Behaviour Research Methods, 41(1), 99-106. https://doi.org/10.3758/ BRM41.1.99.

Panahi, S., Ezatagha, A., Jovanovski, E. and Jenkins, A. (2014). Glycemic effect of oat and barley betaglucan when incorporated into a snack bar: A dose escalation study. Journal of the American College of Nutrition, 33(6), 442-449. https:// doi.org/10.1080/07315724.2013.875366.

Papakonstantinou, E., Orfanakos, N., Farajian, P., Kapetanakou, A.E., Makariti, I.P., Grivokostopoulos, N., Ha, M.A. and Skandamis, P.N. (2017). Shortterm effects of a low glycemic index carobcontaining snack on energy intake, satiety, and glycemic response in normal-weight, healthy adults: Results from two randomized trials. Nutrition, 42, 12 -19. https://doi.org/10.1016/j.nut.2017.05.011.

Poppitt, S.D., Van Drunen, J.D.E., McGill, A.T., Mulvey, T.B. and Leahy, F.E. (2007). Supplementation of a high carbohydrate breakfast with barley $\beta$-glucan improves postprandial glycaemic response for meals but not beverages. Asia Pacific Journal of Clinical Nutrition, 16(1), 1624.

Salleh, S.N., Fairus, A.A.H., Zahary, M.N., Bhaskar Raj, N. and Mhd Jalil, A.M. (2019). Unravelling the effects of soluble dietary fibre supplementation on energy intake and perceived satiety in healthy adults: evidence from systematic review and meta-analysis of randomised-controlled trials. Foods, 8(1), 15. hhtps://doi.org/10.3390/foods8010015.

Schopen, K., Ewald, A.C., Johannes, B.W., Bloch, W., Rittweger, J. and Frings-Meuthen, P. (2017). Shortterm effects of lupin vs. Whey supplementations on glucose and insulin responses to a standardized meal in a randomized cross-over trial. Frontiers in Physiology, 8, 198. https://doi.org/10.3389/ fphys.2017.00198.

Kim, S. Lee, J.W., Heo, Y. and Moon, B. (2016). Effect of Pleurotus eryngii mushroom $\beta$-glucan on quality 
characterisctics of common wheat pasta. Journal of Food Science, 81(4), C835-C840. https:// doi.org/10.1111/1750-3841.13249.

Thondre, P.S. and Henry, C.J.K. (2009). High-molecular -weight barley $\beta$-glucan in chapatis (unleavened Indian flatbread) lowers glycemic index. Nutrition Research, 29(7), 480-486. https://doi.org/10.1016/ j.nutres.2009.07.003.

Thondre, P.S., Wang, K., Rosenthal, A.J. and Henry, C.J.K. (2012). Glycaemic response to barley porridge varying in dietary fibre content. British Journal of Nutrition, 107(5), 719-724. https:// doi.org/10.1017/S0007114511003461.

Westerterp-Plantenga, M.S., Lejeune, M.P.G.M., Smeets, A.J.P.G. and Luscombe-Marsh, N.D. (2009). Sex differences in energy homeostasis following a diet relatively high in protein exchanged with carbohydrate, assessed in respiration chamber in humans. Physiology and Behaviour, 97(3-4), 414419. https://doi.org/10.1016/j.physbeh.2009.03.010.

Wolever, T.M.S. (2013). Is glycaemic index (GI) is a valid measure of carbohydrate quality? European Journal of Clinical Nutrition, 67(5), 522-531. https:/ doi.org/10.1038/ejen.2013.27.

Wolever, T.M., Jenkins, D.J., Jenkins, A.L. and Josse, R.G. (1991). The glycemic index: methodology and clinical implications. The American Journal of Clinical Nutrition, 54(5), 846-854. https:// doi.org/10.1093/ajen/54.5.846.

Wolever, T.M.S., Brand-Miller, J.C. and Abernethy, J. (2008). Measuring the glycaemic index of foods: Interlaboratory study. American Journal of Clinical Nutrition, 87(1), 247S-257S. https://doi.org/10.1093/ ajcn/87.1.247S.

Zafar, T.A., Waslien, C., AlRaefaei, A., Alrashidi, N. and AlMahmoud, E. (2013). Whey protein sweetened beverages reduce glycemic and appetite responses and food intake in young females. Nutrition Research, 33(4), 303-310. http:// dx.doi.org/10.1016/j.nutres.2013.01.008.

Zaremba, S.M.M., Gow, I.F., Drummond, S. and McCluskey, J.T. (2018). Effects of oat $\beta$-glucan consumption at breakfast on ad libitum eating, appetite, glycemia, insulinemia and GLP-1 concentrations in healthy subjects. Appetite, 128, 197 -204. https://doi.org/10.1016/j.appet.2018.06.019. 